\title{
Revitalizing Community and Family Case Study (CFCS) Programme
}

\author{
Fahisham Taib $^{1}$, Nik Mohd Rizal Mohd Fakri ${ }^{2}$ \\ ${ }^{1}$ Department of Paediatrics, ${ }^{2}$ Department of Medical Education, Universiti Sains Malaysia, Kelantan, Malaysia
}

\section{ARTICLE INFO}

$\begin{array}{ll}\text { Received } & : 20 / 03 / 2014 \\ \text { Accepted } & : 27 / 05 / 2014 \\ \text { Published } & : 01 / 09 / 2014\end{array}$

\section{KEYWORD}

Community and family case study

\section{Community}

Education

Student-directed learning

\begin{abstract}
Community and family case study (CFCS) is a community based educational (CBE) programme commenced in 1980 at School of Medical Sciences, Universiti Sains Malaysia. It serves to help and resolve health needs of the individual patients, family and their community. This will help to develop generic skills such as organization, communication and problem solving in relation to local norms, beliefs and socio-cultural influences. Students should have good awareness, sensitivity and empathic response based on health needs and environment that they are living in. Knowledge, skills, attitudes, emotions and values are repeatedly exposed to inculcate optimal learning environment with the community, as well as triggered response by the student to give back to the community by volunteerism. CFCS activism can be revitalized within the individual and group context. This can be achieved by multi-dimensional learning, collaborative effort, effective leadership and supervision, creative programme initiation, effectual research activities and sustainable service to the community. It is hopeful with active community engagement, life experiences learning process, self-directed and reflective learning, students are able to acquire refined attributes such as skills, behaviour, knowledge and attitudes, towards successful personal growth and advancement.
\end{abstract}

(C) Medical Education Department, School of Medical Sciences, Universiti Sains Malaysia. All rights reserved.

CORRESPONDING AUTHOR: Dr Fahisham Taib, Paediatrics Department, School of Medical Sciences, Universiti Sains Malaysia.E-mail: fahisham@gmail.com

\section{Introduction}

Community-based education (CBE) consists of learning activities that utilize the community extensively. This involves enhance learning through problem-based learning (PBL) and service delivered by future doctors who should understand the multidimensional nature of the medical and community problem (1). These students should equip themselves with soft skills knowledge such as teamwork and leadership, and using appropriate network or partnership to reach their CBE goals. Community-based programmes include service-oriented, research-focused and training programs for the community. The programmes will not only allow various ways of staffs and students involvement to the community but also intended to involve participants with hands-on practical knowledge to suit learning objectives and goals.

Community and Family Case Study (CFCS) is an academic curriculum developed by School of Medical Sciences, Universiti Sains Malaysia (USM) with the objective to promote student's participation through various community projects for health development. It is considered as part of important curriculum that emphasize 
on health promotion which is executed during the second and third phase of medical degree. As part of the learning curve, students will have to plan by self-direct learning and execute essential health promotion programme towards the individual, family and community empowerment.

For CBE to succeed and be effective, it will have to have clearly defined objectives and be well planned and organized; will have to inculcate the whole curriculum with its activities starting early and continuing throughout the curriculum years; will have to have the commitment of the total faculty with active participation of all departments and not stand as a function of one department; will have to use active, not passive, learning methods preferably through a problemsolving process and will have to have available resources especially the logistics (7).

\section{Current Programme}

Mohi Eldin et al have classified USM CFCS programmes as a research-based community programme (1) in his taxonomy classification of educational activity. In the public health approach to community project, the students are divided into groups and their task is to identify intended community for profiling and making diagnosis. This is implemented in Phase II Year 3 USM students. The students are required to interview, observe and understand application of epidemiology, understanding the risk factors thus relate all these experiences with the principle of public health in the community. These programmes should be appropriately designed with favourable outcome that benefit the whole community such as preventive, health promotion, motivational and educational health (2).

In the early Phase III Year 4, the approach should tailor on individual and group project. This is done by having learning contracts individually (2-4). Students will have to be involved in 2 projects, individual and group project. In each individual project, students are allowed to choose different spectrum of cases with various learning objectives. Selection of patients usually is set up by supervisor by looking at specific criteria especially patients from low socioeconomic group. Cases selected by individual student must focus on educating patients' chronic medical illness with psychosocial intervention, but with a realistic learning contract. Supervisors' role is to assist and ensure that learning objectives are durable, feasible but yet innovative. There are common obstacles faced by students; that they have selection challenge because many of the patients come from a distanced area within the state or even from neighbouring state like Terengganu. To implement educational activities, multiple visits are needed according to learning contract and agreement. This will encourage gradual process of imparting and transfer of knowledge and skills to the patients. Some students chose to copy the modules initiated by the Ministry of Health in tackling medical or personal health issues. The students are encouraged to have 'birds-eye view' to see the totality of patients' care. Holistic care is better termed at focusing whole person management including medical, psychosocial, relationship, spiritual and emotional dimension. The ultimate success is when students present the learning contract together with evidence of successful change in patients' health status at the end of the project(24). Despite an interesting avenue for the student to get more involved in patients care, attendance to weekly CFCS activity remained poor. This is largely due to overlapping of personal's commitment to parallel undergraduate medical programme. Current review by CFCS committee has suggested a streamlined community programme into allocated time to avoid both students and the supervisors having overlapping school responsibilities.

Group activities can be a challenging output. Each group was given only small amount of petty cash to kick-start a community programme. Sponsorships are vital part to ensure a successful project. This group programme should develop a better experiential learning among the students. However, due to constraint of time and niche which benefit the sponsored group, it becomes a difficult task for the students. Innovative educational programmes which are relevant to the community can be executed with minimal 
budget. The students are required to pull resources by collaborating and networking with different organizations to reduce the cost of the programmes. The twinning programmes involving $\mathrm{MOH}$, primary or secondary schools, colleges or non-governmental organizations have provided, not only expert opinions in the studied field, but also covering financial aspects during the running of the programmes. Students are required to think outside the box by having an original programme, not copied or plagiarism from the senior group. The students must be proactive working together to achieve collective goals and completion of the tasks. Students also have to develop self-educational and supporting materials for each individual patient. Some are creative enough to kick start on formation of community support group, for example for Support Group for Down syndrome in the web, to ensure continuous flow of help, support and advices for parents.

These activities do come with high impact. Impact on patients include holistic medical care, coping strategy, empowering family and patients towards prevention, improving quality of life, free hospital services, financial subsidy, approach to psychosocial intervention which improve the educational and health promotion's role (1). The students may also learn a different perspective of life. Most of the patients are selected from poor background. Hence, experiential learning not only involves communication between the student and the host family but also insertion of humanistic values such as compassion, caring and love. For the university, the whole staffs can start learning and involve through community oriented involvement. This serves as a good opportunity for multidisciplinary team, to participate actively in a voluntary spirit, to provide continuous service to the community.

The basis of active and structured learning for the student includes extensive learning opportunity in community care (5-6). With scarce resources available, students will need to acquire wider knowledge and proactive role to engage community as a whole, towards health promotion and education. This may involve from one to one personal communication as well as competently prescribed clinical skills whilst working in the community. These skills are adopted and integrated from Problem-based Learning (PBL), Problem-Solving Learning (PSL) and Community-based education (CBE) which reflect the core learning strategies. Supervisory role is required by individual group, to ensure students are guided to complete tasks within time frame and agreed learning contract. Supervisor also will have to ensure the milestone of program is adhered according to personal Gant chart agreement. In the climate where the university is pushing for more research based activities, partially adopted research based community program together within individual project are an essential component. This exposure not only leads to long term benefit to the community but also chained of long term programmes for sustainable future. Students may need guidance in the early phase of initiating networking and collaboration. Ambitious students should be allowed for research adventure and exposure with concerted participation of all the group members. Impact for future improvement can be given by direct student feedback mechanism.

\section{Limitation}

During the CFCS project, the supervisors have encountered many technical difficulties and limitations. Interruptive attendance mainly disrupts the learning process. This is primarily despite there are allocated time for student to integrate learning objectives and discussions during week days, the system seems to be over utilized for clinical teachings. This missed opportunity perhaps affects the motivation, commitment and participation in the long run. The assessment for group and individual project has improved recently by giving supervisor the freedom to evaluate them objectively. Quantification of performance can be seen with material presented, improvement of patient's care and resolution of medical, personal and psychosocial issues tackled within the agreed area. Self assessment system can be challenging to identify the best student contribution. Too didactic learning objectives may falsely lead to 
students who are only focused on subject without true altruistic values.

Students may also find difficult to select patients due to repetitive subjects and topics. Thus, supervisor's roles are not only have to widen selected medical cases but ensuring non overlapping cases and preventing plagiarism for maximizes learning. On the other hand, despite budget remains an issue, the fundamental aspect is for a community programme to run as normal. Less sponsorship means smaller and less impactful programme. The core community programme should be towards preventive measures, alleviating health components and supporting ongoing health provision by community engagement process.

The programme needs some invention and revitalization. Traditionally, many students prefer to follow routine learning approach. Many of the projects have been repeatedly completed by the previous year students. The model of community intervention can be copied easily. It is important to emphasize on originality of the projects despite similar projects are running year in and year out. However, impactful program can be heightened by improving number of voluntary workers, re-training of the others and multiorganizations involvement. Creative effort which rarely explored includes using information and communication technology (ICT) to create e-care support. Collaborating networks with government or non-government organizations for the use manpower, food, transport or other resources during the activities should be part of negotiation and planning skills requirement. This outsource budget can minimize spending and further train the students to gain independent collectively. Activity should also run at bigger magnitude to engage larger stakeholders and community together. The aim is trying to gauge students to have different level of experience within state, local or national programme organization.

\section{Suggestion for improvement}

Improvement can be achieved with expert guidance by the supervisors. Students should be geared towards understanding the topic, subject of study and intervention. Most of the supervisors have supervised different CFCS groups as part of the community projects. These multi-sensing learning experiences have given supervisors leverage to improve supervisory skills in patients' selection process, clearer learning contracts, and improved interventional programme and achievable target as part of CBE. Supervisor should have clear vision of what to achieve in individual patients and community education. Documentation of all activities is important to ensure a thorough educational result. Students are required to focus on dispersed learning by covering aspects such as medical, psychosocial and not forgotten the health issue of the extended family members. As students are getting closer to family unit, the supervisor should take the advantage to assess particular unexplored aspect of learning by starting research investigation.

Research based project and program should also be part of the agenda. Simple research questionnaire may be used during the group projects or even at individual level. This can be done as part of pre and post assessment evaluation. High impact writing and publication from the research is achieved from different angle, whether qualitative or quantitative nature. This will not only train students to think laterally but also having enough exposure of future research and becoming a better future doctor. Material prepared for patient's education can be developed further into successful module. The development educational materials leading to publication should be seen as repackage effort for community education. This will become a truly valuable asset of university publications and community contributions.

Networking that usually occurs is within the healthcare system itself. The main players involve Ministry of Health, District Health Centre and even NGOs like Yayasan Orang Kurang Upaya (YOKUK). They are important to bring together cooperation for outreach service and advocacy model. Such collaborative effort required students to open the channel of communication related to inter- and trans- 
disciplinary benefit. Community works should also involve togetherness of the community personnel to achieve health promotion objectives. The common problems that lead to health hazard like active smoking habits should be tackled to prevent long term health consequences. Collaborating with local societies, for example St John's Ambulance, as part of the already sponsored program can be a stepping stone for achieving a greater community project. Student should be allowed to commend their own project using their own initiative and creativity. External fund such as Bahagian Jaringan Industri dan Masyarakat (BJIM) fund can be tapped to commendable project. Some initiatives can also be augmented by inviting charity work from local celebrities into the program to attract much needed crowd participation.

\section{Conclusion}

Many advantages can be achieved from planned and creative community programmes. It needs a focus direction and documentation evidence for supervisor performance index. Many students are doing community work on selective basis following the search for appropriate patient's criteria. There is a need to change the paradigm of behaviour and attitudes towards CFCS programmes. Changes made should direct students towards better cognitive function, improving technical ability and psychomotor, improving relationship, imparting positive habits and affective domain according to Bloom's taxonomy of learning (1956). Awards to student and supervisor are rewarding, however long lasting impact should be a priority to ensure sustainable project in the community.

\section{Acknowledgment}

The author would like to thank all of the undergraduate students and patients involved who persistently teach the author on how to improve healthcare service in the community.

\section{Reference}

1. Mohi Eldin M. A. Magzoub, Henk G. Schmidt. Taxonomy of Community-based Medical Education Acad Med 2000; Vol. 75( 7): 699-707

2. Abdus Salam. Community and Family Case Study: a community-based educational strategy to promote Five Star Doctors for the $21^{\text {st }}$ century. South East Asian Journal of Medical Education 2009; Vol. 3 (1): 20-23

3. Rogayah, J. Mohd Hashim, M.H. Community and Family Case Study Program at the Universiti Sains Malaysia: An experience in self directed, contract learning. Annals of Community Oriented Education 1990; 3: 129-132.

4. Isa, A.R. Mohd Hashim M.H. Rogayah, J. Community and Family Case Study in the Third Phase of USM Medical Curriculum. Diagnosa 1990; Vol. 4(1): 36-41

5. Nor Mohd Adnan Azila, Jaafar Rogayah, Zabidi Azhar Mohd Hussin Curricular Trends in Malaysian Medical Schools: Innovations Within. Ann Acad Med Singapore 2006;35:647-54

6. Shahid Hassan. How to develop a core curriculum in clinical skills for undergraduate medical teaching in the school of medical sciences at Universiti Sains Malaysia? Malaysian Journal of Medical Sciences 2007; Vol. 14(2): 4-10

7. Hamad, B. Community-oriented medical education: What it is? Medical Education 1991;25:16-22 